\title{
Fontes de interesse para a história e a cultura da saúde: o Arquivo Histórico Municipal de Salvador ${ }^{*}$
}

\author{
Sources of interest to the history and culture of \\ health: Arquivo Histórico Municipal de Salvador
}

Maria Teresa Navarro de Britto Matos

Professora do Instituto de Ciência da Informação/Universidade Federal da Bahia

Instituto de Ciência da Informação da Universidade Federal da Bahia

Av. Reitor Miguel Calmon, s/n,

Campus Canela

40110-100 - Salvador - BA - Brasil mariatmatos@terra.com.br

\section{Adriana Sousa Silva}

Arquivista do Arquivo Público da Bahia

Arquivo Público da Bahia

Ladeira de Quintas, 50

40320-140 - Salvador - BA - Brasil drica_cind@hotmail.com
MATOS, Maria Teresa Navarro de Britto; SILVA, Adriana Sousa. Fontes de interesse para a história e a cultura da saúde: o Arquivo Histórico Municipal de Salvador. História, Ciências, Saúde - Manguinhos, Rio de Janeiro, v.15, n.4, out.-dez. 2008, p.1183-1199.

\section{Resumo}

Estudo exploratório, com base em pesquisa documental complementada por consulta bibliográfica, objetivando resgatar a evolução histórico-institucional do Arquivo Histórico Municipal de Salvador (AHMS) e caracterizar a presente estrutura organizacional e seu acervo documental. Destaca as fontes de interesse para a história e a cultura da saúde, custodiadas pelo AHMS.

Palavras-chave: Arquivo Histórico Municipal de Salvador; fontes de história da saúde; Salvador (BA).

\section{Abstract}

Based on documental investigation, supplemented by bibliographic research, this exploratory study recaptures the historical and institutional evolution of Salvador's Municipal History Archives and describes its current organizational structure and documental collection. Special attention is placed on sources of interest to the history and culture of health.

Keywords: Salvador's Municipal History Archives; sources on the history of health; Salvador; Bahia. 
A terminologia arquivística conceitua arquivo histórico como a instituição ou o serviço que tem por finalidade o recolhimento, a custódia, o processamento técnico, a preservação e a difusão de documentos - após o cumprimento das razões pelas quais foram gerados, em função de seu valor permanente, probatório ou informativo -, que deverão ser preservados em caráter definitivo. $\mathrm{O}$ valor permanente é também denominado valor arquivístico ou histórico (Brasil, 2005). Segundo a atual legislação brasileira, os documentos produzidos há mais de 25 ou trinta anos devem ser recolhidos ao arquivo histórico ou permanente (Bellotto, 2005, p.24).

Barros (2008, citado em Cunningham, 2008, p.63) considera que os arquivos históricos "não são mais somente um repositório de documentação que interessa a investigação histórica ...". Na segunda metade do século XX, o papel dos arquivos se amplia, bem como se reconsidera o próprio conceito de "arquivo", que além de custodiar serve "os amplos objetivos sociais, culturais, de responsabilidade democrática ...".

Constituindo lugar de consignação de memórias individuais e coletivas, os arquivos históricos também podem ser locais de esquecimento, caso não exista uma política de salvaguarda e enriquecimento que incorpore a identidade de uma nação ou de uma região; não haja a disponibilidade de investimentos públicos nem a perspectiva de gestão integrada de arquivos e documentos. Nessa visão, os arquivos históricos passam a ser referencial nas tomadas de decisão das administrações públicas e a participar ativamente do processo de modernização do Estado.

No contexto da arquivologia pós-moderna (ou pós-custodial) a atividade de pesquisa deixa de ser isolada e com finalidade específica, e passa a ser estruturante do papel do arquivo histórico na sociedade. E, por isso, o arquivista assume a função de mediador da memória, adotando o contexto da produção documental como referência para preservar e disseminar a informação histórica, o que possibilita, na atividade de pesquisa, a capacidade da área em dialogar com o contexto histórico, e não apenas com seu texto.

Este trabalho vai ao encontro da proposta acima referida, de ampliar o acesso a fontes de interesse para a história e a cultura da saúde, na Bahia e no Brasil. Apresenta o resultado de estudo exploratório, fundamentado em pesquisa documental realizada no acervo do Arquivo Histórico Municipal de Salvador (AHMS), complementada por consulta a fontes bibliográficas, em setembro de 2006. Pretende-se resgatar a evolução histórico-institucional do AHMS, caracterizando a sua estrutura organizacional e o acervo documental que tem sob custódia.

\section{Arquivo Histórico Municipal de Salvador: das origens aos dias atuais}

Para compreender a gênese do AHMS é indispensável conhecer a trajetória das principais bases legais que se constituem em pano de fundo para que seja traçado o processo institucional arquivístico da cidade do Salvador.

A primeira referência identificada na literatura sobre os arquivos de Salvador consta do livro Memórias históricas e políticas da província da Bahia, do coronel Ignacio Accioli de Cerqueira e Silva (1925, p.40), que afirma terem-se perdido na ocasião da invasão dos holandeses (1624-1625) "os archivos da cidade, dos quais somente restaram os volumes de 
registro que D. Fernando José de Portugal mandou restaurar e que se acham na Biblioteca Nacional".

Em História da Câmara Municipal da Cidade do Salvador, Affonso Ruy (1996, p.24) registra que durante a invasão holandesa ${ }^{1}$ (século XVII) muitos papéis do arquivo da Câmara ${ }^{2}$ foram "acumulados, aos montões, em fogueiras ...". Esse fato é também lembrado pelo historiador Alberto Silva (s.d, p.173), em seu livro A Cidade do Salvador: "com a invasão flamenga de 1624, é fato sabido, desapareceu quase de tudo o primeiro Arquivo da Câmara desta nossa cidade".

O livro Memória sobre o estado da Bahia, de autoria de Francisco Vicente Vianna e José Carlos Ferreira (1893, p. 410), destaca que no Palácio do Conselho Municipal existiam "salas de sessões do Conselho, Secretaria e Archivo de um lado ...". No entanto, não foi possível localizar ato oficial que confirme a institucionalização de um arquivo organizado na esfera do poder municipal.

A proposta de criação do Arquivo Municipal como "instituição destinada a guardar e preservar o acervo histórico da cidade" (Teixeira, 1982, citado em Cunha, 2004, p.27) foi apresentada pelo projeto de lei 44 , de 22 de junho de 1915, em reunião do Conselho Municipal.

Mas, quando em visita ao Paço da Câmara em 1927, o historiador Afonso Taunay, de forma enfática relata a situação dos documentos da municipalidade, deixando transparecer que a cidade do Salvador continuava sem arquivo oficial que garantisse a preservação de sua memória histórica. Segundo Antenor Teixeira (1982, p.2), Taunay observou que "o estado de abandono em que se encontrava o tesouro de documentos históricos da municipalidade atirados num esconderijo, sem ar, luz e higiene, bradou, num gesto clínico, apelando para que o poder público o salvasse do seu aniquilamento fatal".

Certamente, o alerta de Taunay contribuiu para que, em 23 de novembro de 1931, o então prefeito Arnaldo Pimenta da Cunha, criasse o Archivo Geral da Prefeitura, pelo ato 112, que estabelecia ser o destino da instituição recolher e conservar todos os manuscritos, impressos e livros produzidos e recebidos pela administração pública municipal, além de centralizar os "archivos parciaes de todas as repartições, secções e serviços" (Salvador, 23 nov. 1931).

A inauguração do Arquivo ocorreu em 10 de abril de 1932, em solenidade festiva, conforme ata lavrada na ocasião, na presença do interventor federal Juracy Montenegro Magalhães, secretários de Estado, o prefeito Arnaldo Pimenta da Cunha, representantes de instituições científicas e culturais, além de grandes personalidades locais (PMS, 1932). Na oportunidade o doutor Pimenta da Cunha, em discurso, destacou:

Durante 107 anos, viveu o Arquivo Público n’uma espécie de cafua ou masmorra o então segredo da Província - situado na pior parte deste edifício. Ninguém dirá que ali devesse permanecer. Era um esconderijo onde ninguém ousaria penetrar. O próprio sol nunca o visitou. A história tão antiga e interessante da cidade do Salvador e documentos outros de valor social estavam a merecer melhor acomodação e maior cuidado (citado em Teixeira, 1982, p.3).

Também em 1932 ocorreu a aprovação do projeto de regulamentação do Arquivo, pelo ato 39, de 11 de abril. Ao abordar, primeiro artigo do capítulo I, a natureza e a organização, o ato evidencia o conceito de arquivo: "uma repartição destinada a conservar, debaixo de 
classificação metódica e sistemática, todos os documentos concernentes a história do antigo Senado da Câmara, na era colonial, e da Câmara Municipal, nos regimens Imperial e Republicano; bem como qualquer outros que a Prefeitura determinar que ali se depositem" (Salvador, 11 abr. 1932).

Quanto à estrutura organizacional, o artigo $3^{\circ}$ do mesmo ato estabelece que o Arquivo Municipal seja dividido em três partes: legislativa, administrativa e histórica. As espécies documentais que compõem cada uma delas são apresentadas nos artigos $4^{\circ}, 5^{\circ}$ e $6^{\circ}$. Na parte histórica (art. $\left.6^{\circ}\right)$, por exemplo, deveriam ser arquivados:

a) todos os livros referentes à historia do município, como sejam: cartas regias, provisões, patentes, alvarás, termos de posses, registro de contas, cartas a S. Magestade, cartas do Governo, arrematações, termos de juramentos;

b) os documentos referentes ao histórico do Patrimônio municipal, sesmarias e confirmações;

c) os livros sobre a ação dos almotacés, alcaidarias, vereações, eleições;

d) os documentos concernentes á creação de distritos urbanos e suburbanos; contas das antigas thesourarias do Senado da Câmara; e todos aquelles que se referirem a fundação de currais e de edifícios públicos da Colônia a Republica;

e) os papeis e documentos que não tiverem classificação especial;

f) os regulamentos, relatórios, memoriais, devassas, exames ou investigações de qualquer gênero;

g) mapas e plantas da cidade, de terras do patrimônio municipal, planos, desenhos roteiros;

h) os livros e documentos que tiverem pertencido as repartições extintas;

i) os modelos ou exemplares de patentes, cartas de diplomas conferidos a Prefeitura em qualquer certamen;

j) as medalhas que tenham sido cunhadas para comemorar assumptos patrióticos ou para prêmios de serviços;

k) todos os documentos historicos de qualquer natureza (Salvador, 11 abr. 1932).

Em razão de reformas administrativas do Poder Executivo municipal, desde 1944 aos dias atuais o modelo institucional do Arquivo foi alterado diversas vezes. As consecutivas mudanças favoreceram a descaracterização da função institucional ${ }^{3}$ de um arquivo público, de gerir, preservar e disponibilizar o acesso aos documentos produzidos e recebidos pelo Poder Executivo, neste caso o municipal.

No entanto, o Arquivo perde sua autonomia administrativa em 23 de maio de 1986, em face de dificuldades conjunturais, como o risco de incêndio no entorno de sua sede, no antigo Solar São Damaso, na rua Mont'Alverne, no Pelourinho. A partir de então, a Fundação Gregório de Mattos (FGM) absorveu o patrimônio e o acervo do Arquivo, por meio do decreto 7.622, que instituiu e aprovou o estatuto da FGM (Salvador, 23 maio 1986).

Considerando a necessidade de implementar uma política de avaliação de documentos produzidos e acumulados pelos órgãos que integram o Poder Executivo municipal, em 23 de outubro de 1990, estabelece-se o decreto 8.759, que dispõe sobre a conservação, preservação e destinação de documentos (Salvador, 23-24 out. 1990).

O Regimento da FGM, aprovado em 19 de julho de 1991 e publicado pelo decreto 9.040, eleva o Arquivo à condição de Gerência do Arquivo Municipal. Em seu art. 10º 
estabelece que a Gerência tenha por finalidade "a gestão do patrimônio documental do Poder Municipal, bem como o estímulo à pesquisa histórica e cultural sobre a Bahia e particularmente sobre Salvador" (Salvador, 21-22 jul. 1991). A partir desse momento, a estrutura organizacional do Arquivo passa a constituir-se de quatro setores: Arquivos Permanentes; Arquivos Correntes e Intermediários; Arquivos Impressos e Biblioteca; e Arquivos Audiovisuais. Nesse mesmo ano, em face da necessidade de disciplinar o recolhimento de impressos editados sob a responsabilidade, às expensas ou por ordem do Executivo municipal, com vistas a preservar a memória administrativa e cultural, em 5 de dezembro foi publicado o decreto 9.236, instituindo o recolhimento de publicações governamentais da Prefeitura Municipal de Salvador (Salvador, 5-6 dez. 1991).

Paralelamente, observamos que em 9 de fevereiro de 1992 foi promulgada a lei 4.508, que instituiu o recolhimento de publicações governamentais da Câmara Municipal de Salvador (Salvador, 9-10 fev. 1992).

O estatuto da FGM foi alterado em 23 de março de 1998, pelo decreto 11.951. O artigo $2^{\circ}$ do capítulo II, "Finalidade e competência", estabelece que a FGM tenha por finalidade "formular e executar a política cultural do município de Salvador". Entre as competências da instituição, duas se referem mais especificamente à área arquivística: os incisos II, "preservar ... divulgar o patrimônio histórico-cultural ...", e V, "promover, desenvolver e administrar atividades de museu, arquivo histórico e demais espaços culturais do Município" (Salvador, 24 mar. 1998, p.2). O art. 9o estabelece a nova estrutura da FGM, que passa a integrar as bibliotecas públicas municipais, por intermédio da Gerência de Arquivos e Bibliotecas (Gerarb).

O Regimento da FGM também foi alterado em 30 de março de 1998, passando a vigorar o decreto 11.962. Na nova conjuntura, conforme registrado no inciso V do artigo 5으, somou-se aos quatro setores - Arquivos Permanentes; Arquivos Correntes e Intermediários; Arquivos Impressos e Biblioteca; e Arquivos Audiovisuais - a Subgerência de Bibliotecas, integrando as bibliotecas municipais existentes. A finalidade (art. 12) da Gerarb passa a ser "a gestão do patrimônio documental e do acervo bibliográfico do Poder Municipal, bem como o estímulo à pesquisa histórica e cultural sobre Salvador" (Salvador, 31 mar. 1998).

\section{Fontes de interesse para a história e a cultura da saúde}

O núcleo documental do denominado AHMS é o acervo acumulado pelo antigo Senado da Câmara, na era colonial, e da Câmara Municipal, durante o Império e a República, cujo conjunto representa parte da memória político-administrativa, socioeconômica e cultural da cidade do Salvador ao longo de quase 460 anos.

Para facilitar o acesso de pesquisadores a esse patrimônio documental, a equipe técnica da atual Gerarb/FGM concebeu e consolidou diferentes instrumentos de pesquisa; para os documentos textuais manuscritos, avulsos e encadernados, por exemplo, existem quatro deles. Todos são inventários sumários que descrevem parcialmente as séries documentais de cada fundo custodiado pelo AHMS, com as respectivas datas-limite. Esses instrumentos encontram-se disponíveis para consulta presencial ${ }^{4}$ e a distância, através da página institucional da FGM (http://www.cultura.salvador.ba.gov.br/index2.php). São eles: 
Inventário Sumário da Documentação Encadernada do Fundo Câmara Municipal (http:/ /www.cultura.salvador.ba.gov.br/downloads/arquivo-historico/textuais/Inventario\%20\%20Fundo\%20C\%E2mara.pdf); Inventário Sumário da Documentação Encadernada do Fundo Intendência Municipal (http://www.cultura.salvador.ba.gov.br/downloads/arquivohistorico/textuais/Inventario\%20-\%20Fundo\%20Intend\%EAncia.pdf); Inventário Sumário da Documentação Encadernada do Fundo Prefeitura Municipal (http://www.cultura. salvador.ba.gov.br/downloads/arquivo-historico/textuais/Inventario\%20-\%20Fundo\% 20Prefeitura.pdf); Inventário Sumário da Documentação Encadernada do Fundo Especial de Certidões (http://www.cultura.salvador.ba.gov.br/downloads/arquivo-historico/textuais/ Inventario\%20-\%20Fundo\%20Certid\%E3o.pdf) e Inventário Sumário da Documentação Encadernada do Fundo Especial Escritura de Compra e Venda de Escravos (http://www. cultura.salvador.ba.gov.br/downloads/arquivo-historico/textuais/Inventario\%20-\% 20Fundo\%20Escravos.pdf). Ainda, existem os Índices dos Livros do Fundo Especial Eleições (http://www.cultura.salvador.ba.gov.br/downloads/arquivo-historico/textuais/Inventario \%20-\%20Fundo\%20Elei\%E7\%E3o.pdf).

Para os documentos bibliográficos e textuais impressos, um catálogo disponibilizado on line (http://bibliotecas.salvador.ba.gov.br/cgi-bin/wxis.exe?IsisScript=phl.xis\&cipar= phl8.cip\&lang=por), no Sistema Municipal de Bibliotecas Públicas de Salvador, integra o acervo de livros, periódicos e publicações governamentais da biblioteca do AHMS.

As fontes iconográficas dispõem de índice por assunto específico.

\section{Documentos textuais manuscritos}

Os documentos textuais manuscritos, avulsos e encadernados somam cerca de 320 metros, constituindo três fundos administrativos, organizados de acordo com o organograma funcional da história administrativa da cidade de Salvador: Câmara Municipal (16241979), Intendência Municipal (1890-1929) e Prefeitura Municipal (1929-1987); e três fundos especiais: Escritura de Compra e Venda de Escravos (1827-1888), Certidões de Nascimento, Casamento e Óbito (1877-1924) e Documentação Eleitoral (1821-1947).

No fundo Câmara Municipal, as séries documentais relacionadas à área de saúde e apresentadas a seguir, têm como datas-limite 1699 e 1889.

- Registro de entrada de navios (1699-1839). Registro do movimento de entrada de navios no porto da cidade do Salvador procedentes, principalmente, de Portugal, mas também de outras partes do mundo. Detalhamento quantitativo de passageiros e tripulação, nome da embarcação e do proprietário, datas de partida e chegada, e conteúdo da carga. Não há, contudo, registro quanto aos nomes de passageiros e/ou tripulação.

- Registro de enjeitados (1701-1736). Registro de crianças abandonadas em instituições soteropolitanas, notadamente recém-nascidas. Constam dados tais como: nome, idade e instituição em que se encontram os ditos enjeitados/abandonados.

- Registro de visitas e exames nas boticas (1761-1827). Registro de visitas nas boticas e casas de drogas na cidade do Salvador e em outras vilas. Constam os nomes do proprietário da botica e da vila ou freguesia em que se localiza.

- Termo de visitas da saúde (1778-1803). Descreve as condições sanitárias e higiênicas de navios, currais, matadouros e açougues. 
- Termo de visitas a embarcações vindas da África (1802-1829). Termo de visitas a embarcações provenientes do continente africano com entrada no porto de Salvador. Encontram-se registrados: nome da embarcação, procedência, período de viagem, nome do mestre, quantitativo de cativos vivos e mortos, e ainda identifica as possíveis moléstias que acometem os sobreviventes.

- Registro de várias ordens da Provedoria-Mor da Saúde (1810-1827). Reúne: vistorias, locais (canto) destinados à venda pública de escravos, atos de nomeação de doutor e guarda-mor da saúde.

- Livro Provedoria da Saúde (1810-1833). Registro de despachos, atos de nomeação de doutor e guarda-mor da saúde, provimentos dos diversos cargos exercidos pela Provedoria da Saúde.

- Cartas de saúde (1810-1841). Registro dos navios que zarparam do porto de Salvador. Contêm nome e tipo da embarcação, procedência, nome do capitão, quantitativo da tripulação e porto de destino.

- Termos de visitas da saúde às embarcações - pecúlio do Lazareto (1811-1827). Registro de saúde de diversas embarcações que atracavam no porto de Salvador e que efetuavam recebimento dos direitos para o Lazareto. Contêm informações como tipo e nome da embarcação, nome de seu mestre, quantitativo de tripulantes, procedência, tempo de viagem e conteúdo do carregamento.

- Confirmações de cirurgiões (1811-1826). Registro de cartas de confirmações de cirurgias e sangrias. Contêm o nome do cirurgião responsável.

- Receita do Provedor-Mor da Saúde (1812-1818). Registro das receitas de boticas e casas de drogas da cidade do Salvador que entraram nos cofres da Provedoria-Mor da Saúde, semestralmente.

- Cartório da Provedoria-Mor da Saúde - escravos (1813-1819). Registro em cartório do escrivão da Provedoria-Mor da Saúde, do juramento de mestres de embarcações que se comprometem a não trazer em cada embarcação mais escravos do que o número permitido.

- Dinheiro recebido pertencente à Provedoria (1813-1815). Registro do dinheiro recebido pela Provedoria-Mor da Saúde relativo às visitas, aos exames e às diligências realizadas.

- Registro de visitas das embarcações atracadas (1814-1817). Relação de exames realizados pelos funcionários da Provedoria-Mor da Saúde nos navios atracados.

- Licença de cirurgias (1818-1828). Registros das licenças concedidas aos cirurgiões para atuar como curandeiros e médicos, em que também se especificam os tipos dos exames permitidos.

- Regimento do físico-mor (1821-1827). Constam nessa série as provisões, as portarias, os editais dos doutores e dos delegados do conselheiro físico-mor do Império do Brasil.

- Devedores e credores da Provedoria da Saúde (1824-1828). Registro das contas dos empregados que recebem ordenados na Provedoria, assim como dos credores e dos devedores.

- Exames de cirurgias e sangrias (1825-1828). Registros dos termos dos exames de cirurgias, de sangrias, de parteiras e de dentistas.

- Registro civil da Provedoria (1826-1828). Relaciona licenças, portarias, ofícios expedidos e recebidos pelas autoridades: provedor-mor da corte, presidente da província, e Senado da Câmara. 


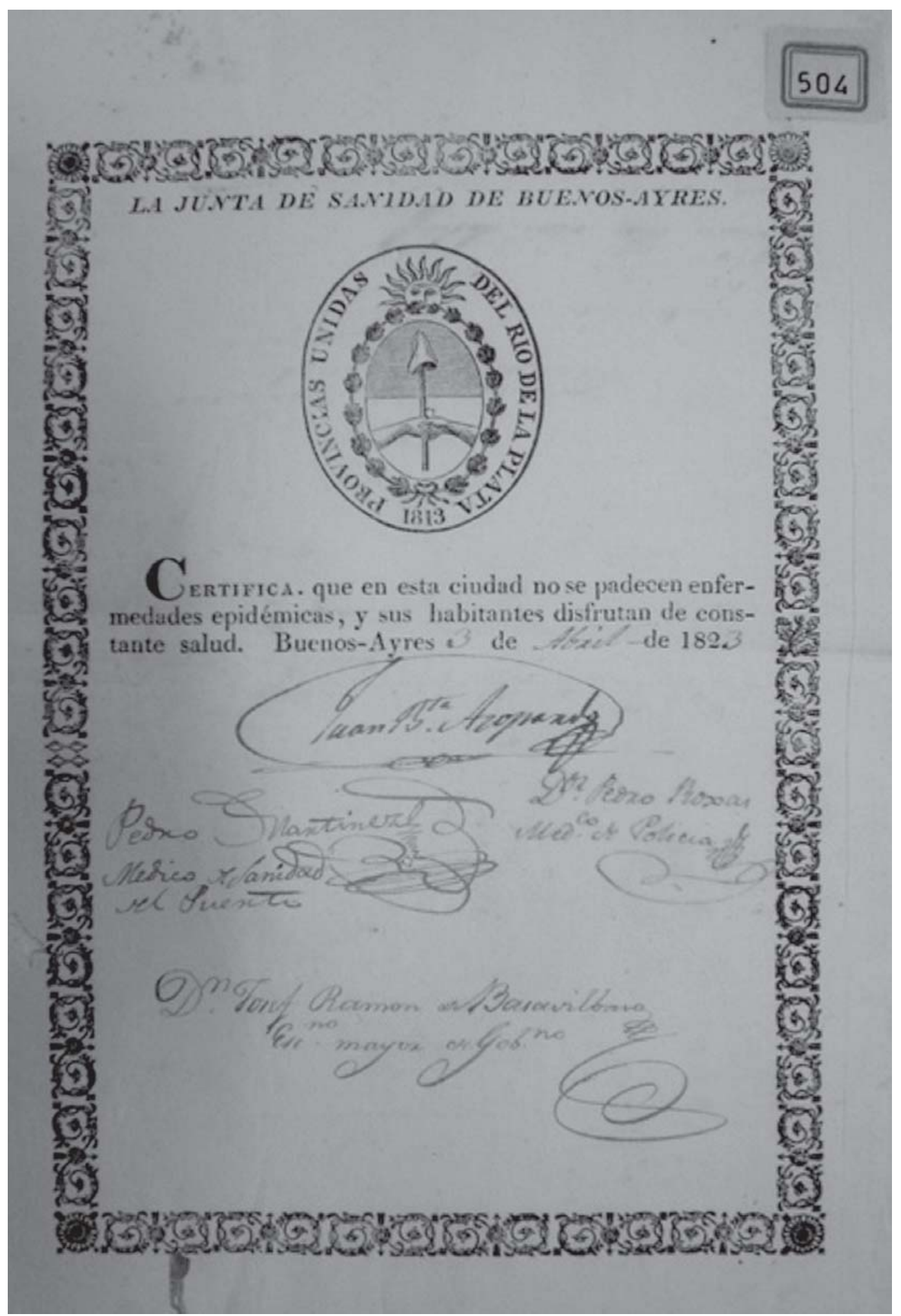

Figura 1: Fundo Câmara, seção Provedoria da Saúde, série Cartas de Saúde, Documentação Avulsa 


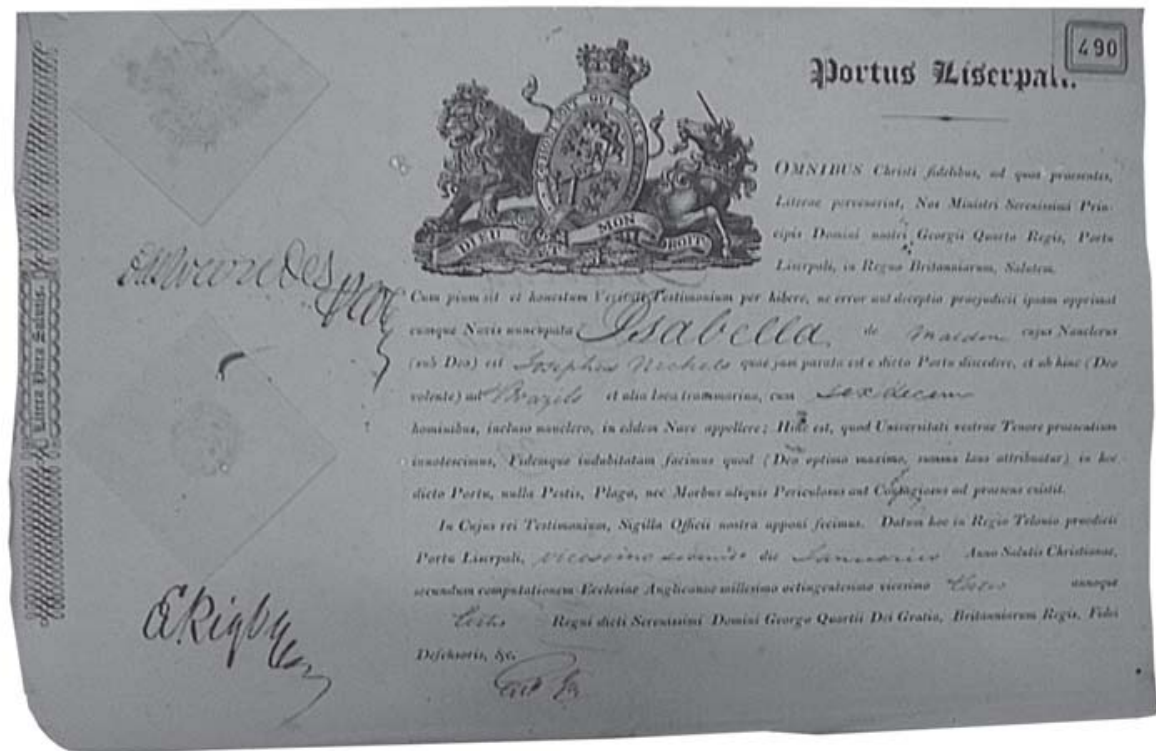

Figura 2: Fundo Câmara, seção Provedoria da Saúde, série

Cartas de

Saúde,

Documentação

Avulsa

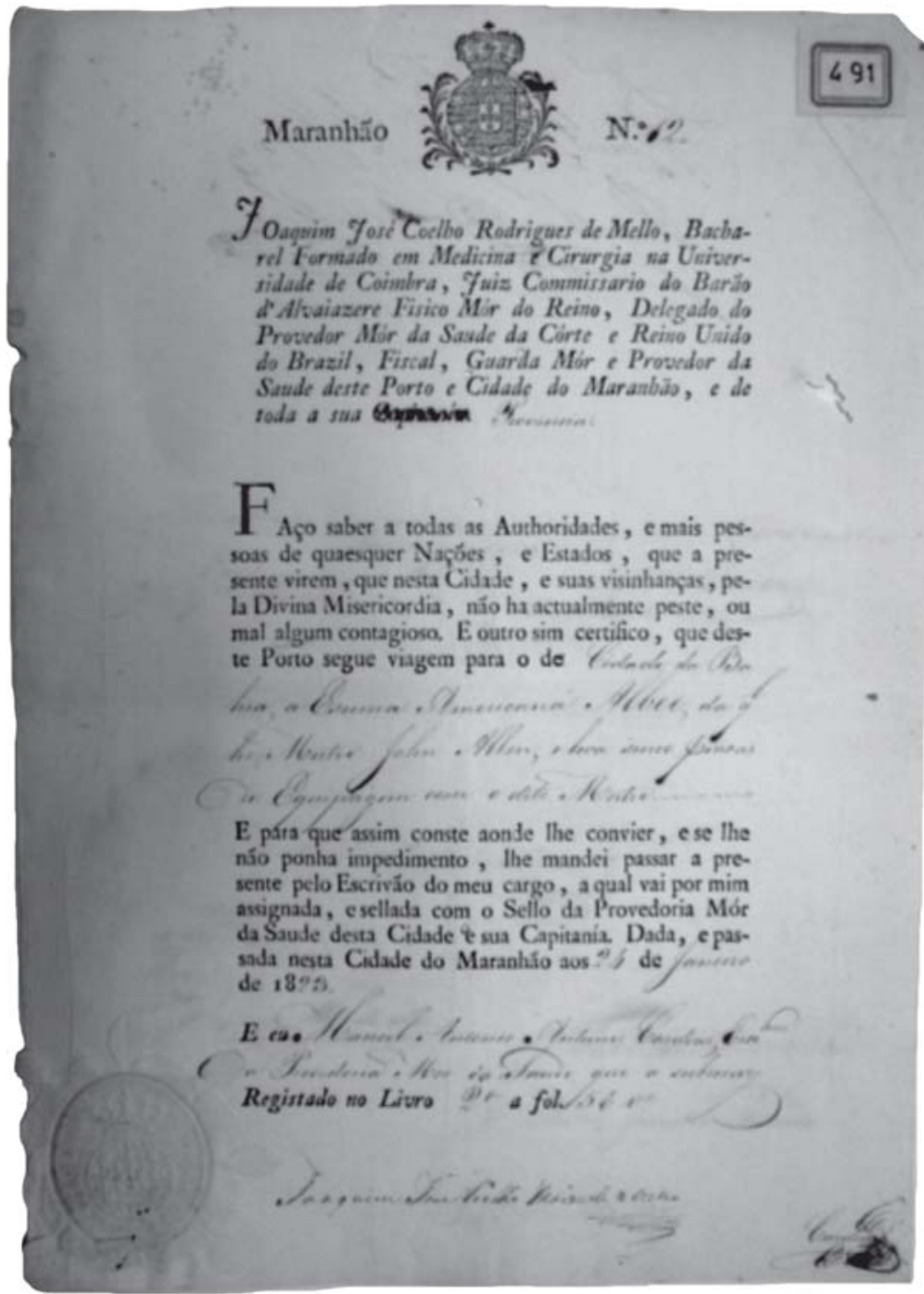

Figura 3: Fundo Câmara, seção

Provedoria da Saúde, série

Cartas de Saúde, Documentação Avulsa 
- Atestado médico (1808-1886). Registro de atestados médicos de funcionários de diversas repartições da Câmara, destacando a justificativa da doença.

- Cartas de saúde (1810-1829). Relação dos documentos emitidos pelo provedor-mor da corte e do reino para os navios de diversas nacionalidades, atestando ou não doenças contagiosas, identificando seu itinerário, quantidade de tripulantes e até mesmo se havia passageiros a bordo.

- Provedoria da Saúde (1814-1862). Constam ofícios de embarcações com entradas no porto de Salvador, requerimentos e ordenados dos empregados da Provedoria para o provedor-mor da Saúde e tesoureiro.

- Conselho de Salubridade (1843-1850). Registros de pedidos de vistoria em lugares considerados sujos e propícios à contração de doenças e problemas pelo excesso de fumaça.

- Médico do Município (1849-1869). Registros de ofícios, requerimentos e atestados do médico da municipalidade, referentes a doenças e vistorias nos matadouros públicos.

- Inspetoria de Higiene da Bahia (1853-1889). Registro de ofícios e requerimentos da Inspetoria de Higiene da Província da Bahia para o presidente da Câmara e demais autoridades do município, relacionados à limpeza da cidade, que envolve as condições do lixo e da higiene da água que abastece a cidade de Salvador.

- Empresa de Asseio da Cidade (1878-1888). Registro de requerimentos e ofícios recebidos e expedidos referentes ao asseio da cidade, à utilização de carroças, aos condutores de carros e aos contratos celebrados.

- Posturas Municipais (1650-1936). Relação das leis locais submetidas à aprovação do Poder Provincial, definindo sua aplicação no cotidiano da cidade.

- Santa Casa de Misericórdia (1733-1890). Registro de ofícios, requerimentos e cartas recebidos da Santa Casa, bem como ofícios internos da esfera municipal dando tramitação a despachos dos documentos e outras requisições da instituição.

Somam-se ainda outros documentos administrativos que registram o cotidiano do governo na época, relativos à gestão da saúde municipal, como, por exemplo, atas da Câmara, provisões reais, cartas do Senado, provisões do governo, bem como folhas de pagamento e outros documentos do Tesouro.

No fundo Intendência Municipal, as fontes de interesse para a saúde, conforme abaixo identificadas, têm como datas-limite 1896 e novembro de 1929.

- Matrícula de vendedores de leite (1896). Registro dos nomes e matrículas desses trabalhadores, cadastrados pela Diretoria de Higiene Municipal.

- Folhas de pagamento da Assistência Pública (1902-1926). Discriminam os proventos e os respectivos nomes dos funcionários da Diretoria da Assistência Pública do Município.

- Memorando da higiene municipal (1905-1924). Memorandos expedidos para diversas repartições da Intendência municipal, relacionados a vistorias, coleta de lixo, obras na cidade e assuntos de interesses dos funcionários da Higiene Municipal.

- Registro de açougues (1906-1921). Inclui, por distrito, nomes dos proprietários e números dos estabelecimentos, e do pagamento de tarifas.

- Registro de estábulos (1907-1930). Inclui nomes dos proprietários, ruas, freguesia, número do estabelecimento e pagamento de tarifas. 
- Pedido de asseio - informação de delegado (1909-1924). Registros de informações das visitas efetuadas pelos delegados de diversos distritos para questões relacionadas ao asseio das casas e da cidade do Salvador.

- Registro de documentos arquivados da Assistência Pública (1915). Inclui nomes dos remetentes, assuntos dos documentos, despacho e data do arquivamento.

- Registro da entrada e destino das petições (1917-1923) que tramitaram na Diretoria de Higiene e Assistência Pública, com nomes dos remetentes, data de entrada, objeto das petições e nome do delegado responsável pela vistoria.

- Registro das saídas e destinos de ofícios (1917) da Diretoria da Higiene e Assistência Pública Municipal, com nomes de remetentes, endereços e assuntos.

- Entrada de medicamentos (1907). Registros de lançamentos de entrada e quantidades fornecidas pelos pedidos.

- Registro de fórmulas (1911-1928) despachadas pela Farmácia Municipal para diversas repartições da Intendência Municipal de Salvador.

- Diretoria de Laboratório Municipal (1890-1924). Ofícios, requerimentos e análises feitas em diversos estabelecimentos e entidades, com materiais de gêneros alimentícios de casas comerciais. Constam ainda os relatórios dos trabalhos feitos pelo Laboratório Municipal.

- Diretoria de Higiene e Assistência Pública Municipal (1913-1929). Ofícios e requerimentos, demonstrativo financeiro, licenças para estábulos e vistorias nos cemitérios da cidade.

- Diretoria de Assistência Pública. Asilo de Mendicidade (1913- 1929). Ofícios, requerimentos e prestações de contas para a Diretoria de Assistência Pública, além das folhas de pagamento dos funcionários contratados pelo Asilo.

O fundo Prefeitura Municipal abrange o período de 1929 a 1959, reunindo os documentos abaixo:

- Santa Casa de Misericórdia (1929-1954). Registro de ofícios, requerimentos e cartas recebidas da Santa Casa de Misericórdia, bem como ofícios internos da esfera municipal dando tramitação a despachos dos documentos e outras requisições da Santa Casa.

- Diretoria de Assistência Pública. Asilo de Mendicidade (1930-1959). Ofícios, requerimentos e prestações de contas para a Diretoria de Assistência Pública, além das folhas de pagamento dos funcionários contratados pelo Asilo.

- Registro de fórmulas (1930-1940). Registros de lançamentos das fórmulas despachadas pela Farmácia Municipal para diversas repartições da Prefeitura Municipal de Salvador.

- Seção de Água e Esgoto (1932-1952). Ofícios e requerimentos relacionados aos serviços de águas e esgotos do Governo do Estado da Bahia para a Prefeitura Municipal de Salvador.

- Registro de profissionais do Asilo de Mendicidade (1937-1939).

- Atestado médico (1940). Registro de atestados médicos de funcionários de diversas repartições da Câmara, destacando a justificativa da doença.

- Registro de açougues (1946) do município da capital por distrito, com nomes dos proprietários e números dos estabelecimentos e do pagamento de tarifas.

\section{Documentos bibliográficos e textuais impressos}

Entre os documentos bibliográficos e textuais impressos, o AHMS dispõe do total de três mil livros relativos a aspectos socioeconômico-histórico-culturais da cidade de Salvador, 
além das publicações governamentais (notadamente Diário Oficial; leis e decretos; planos de governo; relatórios de gestão e mensagens) editadas pela Prefeitura Municipal e pela Câmara Municipal de Salvador, bem como 46.300 clippings de jornais locais, sendo oito pastas com mais de quinhentos recortes sobre saúde em Salvador, tratando de assuntos como cursos de higiene para baianas de tabuleiro, fiscalização, inaugurações de unidades médicas, campanha de combate ao fumo, denúncias sobre o abandono de postos médicos, greves, distribuição de preservativos, vacinação, entre outros.

Os livros selecionados no catálogo disponibilizado no Sistema Municipal de Bibliotecas Públicas de Salvador relacionados à saúde na Bahia são:

- Alves, Isaias. Educação e saúde na Bahia: na interventoria Landulpho Alves (abril 1938junho 1939). Salvador: Bahia Gráfica e Editora, 1939. 165p. Publicação do Governo do Estado da Bahia/Secretaria de Saúde.

Resumo: Relatório das atividades da Secretaria de Educação e Saúde entre 11 de abril de 1938 e 30 de junho de 1939.

- Bahia. Secretaria de Educação e Cultura. Fundação do Patrimônio Artístico e Cultural. Estudo de morbidade no Maciel. Salvador: Secretaria de Educação e Cultura, 1976. 44f. Resumo: $\mathrm{O}$ estudo constitui, na área de saúde, o passo inicial de uma série de pesquisas específicas (Maciel), servindo de subsídio ao planejamento de atenção médica integrada ao amplo trabalho de recuperação física e socioeconômica desenvolvido pela Fundação na área.

- Caprara, Andréa. Polissemia e multivocalidade da epilepsia na cultura afro-brasileira. In: Caroso, Carlos; Bacelar, Jeferson (Org.). Faces da tradição afro-brasileira. Rio de Janeiro: Pallas, 1999, p.257-288.

Resumo: Trabalho voltado para o interesse de diferenciar as crises epilépticas das formas de possessão no candomblé.

- Costa, Paulo Segundo da. Hospital de Caridade (São Cristovão/Santa Izabel) da Santa Casa de Misericórdia da Bahia: 450 anos de funcionamento 1549-1999. Salvador: Contexto, 2000. 136p.

- Costa, Paulo Segundo da. Ações sociais da Santa Casa de Misericórdia da Bahia. Salvador: Contexto, 2001. 180p.

Resumo: Registra (por ocasião dos 450 anos da Santa Casa de Misericórdia da Bahia) a ação benemérita desenvolvida pela instituição desde 1549 no referido Hospital da Caridade e ininterruptamente até nossos dias no moderno Hospital Santa Izabel.

- Miranda, Carlos Alberto Cunha. A arte de curar nos tempos da Colônia: limites e espaços da cura. Recife: Fundação de Cultura Cidade do Recife, 2004. 486p.

Resumo: Explora exaustivamente os episódios bélicos, entre eles os da chamada Guerra dos Bárbaros, nos sertões predatórios da colonização, em conseqüência do que as práticas culturais e, nelas, as terapias mágicas dos indígenas são demonizadas e reprimidas.

- Pedreira, Pedro Tomás. A Santa Casa de Misericórdia de Santo Amaro. Salvador: [s.n.], 1978. 121p. Edição comemorativa do bicentenário.

Resumo: Divulga aspectos da história da Santa Casa de Misericórdia de Santo Amaro, com base em documentação, até agora inédita, existente na Seção de Manuscritos da Biblioteca Nacional e no Arquivo Nacional, do Rio de Janeiro. Além do histórico, contém fac-símile dos documentos. 
- Santa Casa de Misericórdia da Bahia. Relatório. Salvador: [s.n.].

Resumo: Relatórios de atividades da instituição referentes à segunda metade do século XX: 1963, 1971, 1972, 1974, 1976, 1978, 1979, 1983 e 1984.

- Silva, Cecília Luz da. A cidade do Salvador nos seus 454 anos. Salvador: Eduneb, 2005. 197p.

Resumo: Reúne os principais acontecimentos que marcam a cidade, desde sua construção até os dias atuais.

- Superintendência de Estudos Econômicos e Sociais da Bahia - SEI. Serviços estratégicos na Região Metropolitana de Salvador. Salvador: SEI, 2004. 147p. (Estudos e Pesquisas, 70). Resumo: Com base na literatura internacional especializada, analisa a terceirização dos serviços em geral, aí incluídos os de saúde.

- Universidade Católica do Salvador. Faculdade de Ciências Econômicas. Economistas de 1970: dez anos de economia baiana. Salvador: Universidade Católica do Salvador. 19-?.235p.

- Vianna, Francisco Vicente; Ferreira, José Carlos. Memória sobre o Estado da Bahia. Salvador: Diário da Bahia, 1893. 647p.

Resumo: Obra concluída para atender à solicitação do governador do estado, Joaquim Manuel Rodrigues Lima, com a finalidade de integrar a Exposição de Chicago (1892), com "notícia minuciosa sobre o estado da Bahia, que deverá constar principalmente da descrição política e geográfica, suas riquezas naturais ...", incluindo hospitais, enfermarias, casa de saúde, asilos e cemitérios.

As publicações governamentais, de certa forma, funcionam como "espelhos das funções de um governo e de suas agências e seus instrumentos e suas subvenções" (Childs, 1973, citado em Campello, Cendón, Kremer, 2000). As que integram o catálogo disponibilizado no Sistema Municipal de Bibliotecas Públicas de Salvador relacionados à saúde na Bahia são:

- Intendência Municipal. Relatório apresentado ao Conselho Municipal pelo Dr. Francisco de Paula O. Guimarães - 1899: na sessão solene de posse do seu substituto Dr. Jose Duarte Freire de Carvalho Filho. Salvador: Correio de Notícias, 1900. 311p.

- Intendência Municipal do Estado da Bahia. Código de Posturas Municipais: Cidade do Salvador. Salvador: Imprensa Oficial do Estado, 1921. 135p.

Resumo: Trata-se de código oficializado pelo intendente e pelo Conselho Municipal e que engloba posturas voltadas para higiene e saneamento do município.

- Moraes, Luiz Roberto Santos. Recursos hídricos, saneamento e saúde. In: Prefeitura Municipal de Salvador. Secretaria do Meio Ambiente (Ed.). Planejamento ambiental para Salvador. Salvador: PMS, 1995, p.139-226.

- Mota, Eduardo Andrade. Água e saúde na cidade de Salvador. In: Prefeitura Municipal de Salvador. Secretaria do Meio Ambiente; Goethe Institut. Águas e turismo: Seminário Águas e Turismo na Região Metropolitana de Salvador e Litoral Norte. Pref., Ulrich Gmunder; introd., Juca Ferreira. Salvador: PMS; Goeth Institut, 1994, p.219-236.

- Prefeitura Municipal do Salvador. Secretaria Municipal de Educação e Cultura. Departamento de Cultura. Uma fonte para pesquisa histórica. Salvador: PMS, 1977. c.30p. Inclui reprodução de documentos originais. (Cultura e Arte na Bahia). 
Resumo: Reúne documentos intitulados 'marca de escravo'; trata-se de petições apresentadas ao provedor da saúde por proprietários cujos escravos recém-importados estivessem em quarentena ou hospitalizados em enfermarias e para os quais pedim liberação. As 'cartas de saúde' são documentos expedidos pelas autoridades portuárias aos comandantes dos navios, especificando o estado de saúde de seus tripulantes. A 'visita da saúde' era obrigatória à chegada em qualquer porto e só depois desse procedimento era concedida licença para desembarque de mercadorias e passageiros.

- Prefeitura Municipal do Salvador. Políticas, diretrizes e linhas de ação para o desenvolvimento municipal. Projeto de ação apresentado pelo prefeito Manoel Figueiredo Castro. Salvador: Prefeitura Municipal do Salvador, 1984. 77p.

Resumo: Considerações relativas aos problemas que condicionam a situação da cidade e às questões que envolvem a saúde.

- Prefeitura Municipal do Salvador. Secretaria Municipal de Ação Social. Creche comunitária. Salvador: PMS, 1991. 68p.

- Prefeitura Municipal do Salvador. Secretaria Municipal de Saúde. Manual de reorientação odontológica. Org., Maria do Carmo Galvão e Oliveira. Salvador: PMS, 1992. 25p.

Resumo: Proposta de reorientação odontológica da Secretaria Municipal de Saúde, com o objetivo de proteger e recuperar a saúde bucal da população, mediante medidas preventivas e curativas básicas.

- Prefeitura Municipal do Salvador. Secretaria do Meio Ambiente. Goethe Institut. Águas e turismo: Seminário mananciais e usos, saneamento e saúde, política e legislação. Prefácio, Ulrich Gmunder; introd., Juca Ferreira. Salvador: PMS; Goethe Institut, 1994. 368p.

- Ribeiro, Ana Christina Lordelo de Salles. Manual de procedimentos técnicos de enfermagem. Salvador: PMS/Secretaria Municipal de Saúde/Coordenadoria de Desenvolvimento de Recursos Humanos/Subcoordenadoria de Capacitação, 1992.

Os artigos de periódicos que integram o catálogo disponibilizado no Sistema Municipal de Bibliotecas Públicas de Salvador relacionados à saúde na Bahia são:

- Albuquerque, Anselmo Pires de. O centenário médico de 1932: faz cem anos foram transformados em Faculdade de Medicina os Colégios Médico-Cirúrgicos do Brasil. Revista do Instituto Geográfico e Histórico da Bahia, Salvador, n.58, 1932, p.443-453.

Resumo: Número consagrado aos cem anos da Faculdade de Medicina.

- Carvalho, Antonio Pedro Alves de. A saúde no planejamento urbano de Salvador. Veracidade, Salvador, v.2, n.4, dezembro de 1992, p.41-51.

Resumo: Considera diversos planos governamentais com vistas a uma avaliação das ações de saúde, de 1939 a 1980. O planejamento setorial evoluiu da simples reação frente a problemas sanitários episódicos, de farto vocabulário médico, passando por intervenções autoritárias de expulsão de moradores de cortiços até planos de certo tom liberal. A saúde pública é assumida como obrigação do Estado.

- Freitas, Mário Sebastião. A implantação do Sistema Único de Saúde - SUS. Veracidade, Salvador, v.1, n.1, julho-setembro de 1991, p.33-36.

Resumo: Aprofundando o processo de democratização do setor, o Plano Municipal de Saúde de Salvador eleva o número de unidades básicas de atendimento de 77 para 91. Ao mesmo tempo, um fundo especial, leis e orientações técnicas viabilizam melhor 
gerenciamento do SUS - uma conquista nacional. Isso representa alento numa cidade que padece de graves enfermidades, com péssima distribuição de renda e cuja Prefeitura se encontra em grave crise financeira. Ressalta que a implantação dos distritos sanitários, a informatização do setor e a melhor administração do sistema podem atenuar os problemas, se houver sincronia entre as intenções e os recursos efetivamente mobilizados para a Saúde.

- First, Asher Kiperstok. A cólera ensina, mas nós queremos aprender? Veracidade, Salvador, v.2, n.3, setembro de 1992, p.14-18.

Resumo: Aborda especificamente o quadro sanitário de Salvador no final do século XX. Destaca a população atendida pelos serviços de saneamento, bem como o custo de implantação dos sistemas de abastecimento de água. Aponta os altos investimentos como fator explicativo da presença dessa doença tão antiga e que já havia sido considerada erradicada do nosso convívio.

- Silveira, José. Liga Baiana Contra a tuberculose. Revista do Instituto Geográfico e Histórico da Bahia, Salvador, n.90, 1992, p.101-110.

Resumo: Estudo sobre a tuberculose na Bahia.

- Vieira Nascimento, Anna Amélia. A Cholera morbus (Colera) como fator de involução populacional na cidade de Salvador. Anais do Arquivo do Estado da Bahia, Salvador, v.45, 1981.291p.

\section{Documentos iconográficos}

As fontes iconográficas são compostas de 32.607 fotografias, 2.856 cartões-postais, 12.255 slides, 141 filmes em 16mm e 35mm das décadas de 1940 a 1980, todos relativos a eventos administrativos, cívicos e populares; 6.361 projetos arquitetônicos de 1890 a 1953; e 639 partituras musicais manuscritas e impressas, produzidas nos séculos XIX e XX por compositores baianos de música sacra e popular.

A documentação referente à área de saúde é encontrada nos fundos: Prefeitura Municipal de Salvador, jornal Diário de Notícia e jornal O Estado de São Paulo, sendo em sua maioria fotografias em preto-e-branco. O acervo de fotografias dispõe de imagens relativas a campanhas de vacinação, congressos da área médica, escolas de medicina, fachada de hospitais, laboratórios, retratos de médicos, pesquisas na área de saúde, entre outros.

\section{Considerações finais}

Os dados aqui apresentados revelam conjunto bastante diversificado de fontes de interesse para a história e a cultura da saúde.

Vale observar, ainda, que para a historiografia brasileira, o acervo do AHMS é significativo, importante e raro. De fato, abrange o período em que Salvador foi a primeira capital do Brasil colonial, quando se iniciou toda a nossa história. Sendo assim, a consulta às fontes custodiadas e disponibilizadas pelo AHMS permite que o pesquisador acadêmico-cientifico possa resgatar os principais fatos e personagens da história dessa cidade. Oxalá a memória da saúde soteropolitana ganhe espaço e presença na história da saúde. 


\section{NOTAS}

* Uma primeira versão deste trabalho foi apresentada no I Fórum de História das Ciências e da Saúde na Bahia, realizado no Centro Federal de Educação Tecnológica da Bahia (Cefet), em outubro de 2006.

${ }^{1}$ O Livro do Tombo do Mosteiro de São Bento afirma que apenas os monges beneditinos conseguiram conservar registros documentais produzidos antes da invasão holandesa, porque deixaram o mosteiro levando os documentos consigo. Vale lembrar que, logo após a saída desses invasores, os documentos passaram por processo de restauração e todos foram registrados no tabelião de notas que existia na época.

${ }^{2}$ Segunda a ser instalada no Brasil, na ordem cronológica de criação, "exercendo desde logo preponderante influência nos destinos da terra como cabeça da colônia” (Ruy, 1996, p.39).

${ }^{3}$ Note-se que, posteriormente, foram estabelecidos dispositivos legais por meio dos incisos XIV e XXXIII do artigo $5^{\circ}$, do inciso III do artigo 23, no artigo 215 , no inciso IV e nos parágrafos $1^{\circ}$ e $2^{\circ}$ do artigo 216 da Constituição Federal de 1988, assim como nos artigos 5, $9^{\circ}$ e $21^{\circ}$ da Lei Federal de Arquivos, 8.159, de 1991, para o pleno cumprimento de tais funções.

${ }^{4}$ O AHMS/FGM localiza-se na rua Chile, 31, Centro Histórico, Salvador, Bahia.

\section{REFERÊNCIAS}

BARROS, Fátima.

Arquivos históricos nos dias de hoje: aliciantes desafios, múltiplos papéis. Disponível em: www:// http://badinfo.apbard.pt/Congresso9/ COM79.pdf. Acesso em: 1 set. 2008. s.d.

BELLOTTO, Heloisa Liberalli.

Arquivos permanentes: tratamento documental. 3.ed. Rio de Janeiro: Ed. FGV. 2005.

BRASIL.

Arquivo Nacional. Dicionário brasileiro de terminologia arquivística. Rio de Janeiro: Arquivo Nacional. 2005.

CAMPELLO, Bernadete Santos; CENDÓN, Beatriz Valadares; KREMER, Jeannette Marguerite (Org.).

Fontes de informações para pesquisadores e profissionais. Belo Horizonte: Editora UFMG. 2000.

CHILDS, James Bennett.

Government publications (documents). In: Kent, Allen; Lancour, Harold; Daily, Jay E. (Ed.). Encyclopedia of library and information science. v.10. New York: M. Dekker. p.36-140. 1973.

CUNHA, Vanda Angélica da.

Memória, sociedade e mídia impressa: a experiência do Arquivo Histórico Municipal de Salvador. Salvador: Fundação Gregório de Mattos. 2004.

CUNNINGHAM, Adrian.

A alma e a consciência do arquivista: reflexões sobre o poder, a paixão e o positivismo de uma profissão missionária. Cadernos BAD, Lisboa, n.2, p.63. 2003.
PMS.

Prefeitura Municipal do Salvador. Acta da inauguração do Archivo Geral da Prefeitura. Salvador: [s.n.]. 1932.

RUY, Afonso.

História da Câmara Municipal da Cidade de Salvador. 2.ed. Salvador: Câmara Municipal de Salvador. 1996.

SALVADOR.

Decreto 11.962, de 30 de março de 1998. Altera o Regimento da Fundação Gregório de Mattos - FGM e dá outras providências. Diário Oficial do Município, Salvador, p.2-7. 31 mar. 1998.

SALVADOR.

Decreto 11.951, de 23 de março de 1998. Altera o Estatuto da Fundação Gregório de Mattos FGM e dá outras providências. Diário Oficial do Município, Salvador, p.2-3. 24 mar. 1998.

SALVADOR.

Lei 4.508, de 9 de fevereiro de 1992. Institui o recolhimento de publicações governamentais na Câmara Municipal de Salvador, para fins de preservação da memória do Município. Diário Oficial do Município, Salvador, p.4. 9-10 fev. 1992.

\section{SALVADOR.}

Decreto 9.236, de 5 de dezembro de 1991. Institui o recolhimento de publicações governamentais da Prefeitura Municipal de Salvador e dá outras providências. Diário Oficial do Município. Salvador, p.3. 5-6 dez. 1991.

SALVADOR.

Decreto 9.040, de 19 de julho de 1991. Aprova o Regimento da Fundação Gregório de Mattos 
- FGM e dá outras providências. Diário Oficial do Município. Salvador. 21-22 jul. 1991.

\section{SALVADOR.}

Decreto 8.759, de 23 de outubro de 1990. Dispõe sobre a conservação, preservação e destinação de documentos, e dá outras providências. Diário Oficial do Município, Salvador, p.2. 23-24 out. 1990.

SALVADOR.

Decreto 7.622. Institui e aprova o Estatuto da Fundação Gregório de Mattos - FGM, e dá outras providências. Diário Oficial do Município, Salvador. 23 maio 1986.

\section{SALVADOR.}

Ato 39. Regulamento do Archivo Geral da Prefeitura. 11 abr. 1932.

\section{SALVADOR.}

Ato 112. Criação do Archivo Municipal. 23 nov. 1931.
SILVA, Alberto.

A cidade do Salvador (aspectos seculares). Salvador: Prefeitura Municipal de Salvador; Livraria Progresso. (Coleção de Estudos Brasileiros, Série Marajoara, 17). s.d.

SILVA, Ignacio Accioli de Cerqueira e. Memórias históricas e políticas da província da Bahia. v.2. Anotador, Braz do Amaral. Salvador: Imprensa Official do Estado. 1925.

TEIXEIRA, Antenor.

Arquivo Municipal da Cidade do Salvador. [Salvador: s.n.].1982.

VIANNA, Francisco Vicente; FERREIRA, José Carlos.

Memória sobre o estado da Bahia. Salvador: Diário da Bahia. 1893. 